Article

\title{
Life-Cycle and Energy Assessment of Automotive Component Manufacturing: The Dilemma Between Aluminum and Cast Iron
}

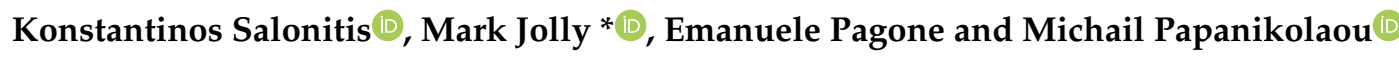 \\ Manufacturing Theme, Cranfield University, Cranfield, Bedford, MK43 0AL, UK \\ * Correspondence: m.r.jolly@cranfield.ac.uk; Tel.: +44 (0)1234 758347
}

Received: 6 June 2019; Accepted: 30 June 2019; Published: 3 July 2019

check for updates

\begin{abstract}
Considering the manufacturing of automotive components, there exists a dilemma around the substitution of traditional cast iron (CI) with lighter metals. Currently, aluminum alloys, being lighter compared to traditional materials, are considered as a more environmentally friendly solution. However, the energy required for the extraction of the primary materials and manufacturing of components is usually not taken into account in this debate. In this study, an extensive literature review was performed to estimate the overall energy required for the manufacturing of an engine cylinder block using (a) cast iron and (b) aluminum alloys. Moreover, data from over 100 automotive companies, ranging from mining companies to consultancy firms, were collected in order to support the soundness of this investigation. The environmental impact of the manufacturing of engine blocks made of these materials is presented with respect to the energy burden; the "cradle-to-grave approach" was implemented to take into account the energy input of each stage of the component life cycle starting from the resource extraction and reaching to the end-of-life processing stage. Our results indicate that, although aluminum components contribute toward reduced fuel consumption during their use phase, the vehicle distance needed to be covered in order to compensate for the up-front energy consumption related to the primary material production and manufacturing phases is very high. Thus, the substitution of traditional materials with lightweight ones in the automotive industry should be very thoughtfully evaluated.
\end{abstract}

Keywords: Manufacturing; energy efficiency; life-cycle assessment; aluminum; cast iron

\section{Introduction}

Over the years, the material selection for modern car components changed a lot. As a reference, in the 1970s, a design engineer would have to select from four to five sheet forming grades, whereas today there are more than 50 options [1]. A number of material selection criteria need to be considered including corrosion and wear resistance, crashworthiness, and manufacturability. At the same time, legislation pushes for lighter vehicles, on the basis that lighter cars result in lower fuel consumption. Since 1995 in Europe, the average car $\mathrm{CO}_{2}$ emission requirement dropped from $186 \mathrm{~g} / \mathrm{km}$ to $161 \mathrm{~g} / \mathrm{km}$ in 2005, and it is expected to further reduce to $95 \mathrm{~g} / \mathrm{km}$ in 2021 [2]. For achieving these requirements, automotive manufacturers opt to use aluminum alloys in vehicles as a "lightweight" material. The average usage of aluminum (Al) in a passenger car varies from $12 \%$ to $60 \%$ depending on the vehicle. With regard to cast $\mathrm{Al}$ alloys, these are mostly used for engine blocks, cylinder heads, and wheels, although they are increasingly used for nodes in the chassis structure and can potentially reduce weight by $40 \%$.

Substituting with lower-density materials leads to lower tailpipe emissions; however, this does not consider the $\mathrm{CO}_{2}$ footprint of the materials used in the manufacturing of vehicles. The $\mathrm{CO}_{2}$ footprint of 
any material is related to its embodied energy, which is a synonym of the "track record" of a material and the way it is produced. In every production phase, energy is needed for changing the phase, geometry, and properties of the material. This energy is, thus, virtually embodied in the material. Ashby et al. [3] presented the embodied energy of producing components for the automotive industry and discussed the contribution of each life-cycle phase. According to their investigation, the energy involved during the use phase of a vehicle is much larger than that during the material extraction and manufacturing phase. Similar conclusions were reached by Sorger et al. [4] who investigated the effects of substituting an aluminum cylinder block with a newly developed one made of cast iron (CI). Their results showed that the $\mathrm{CI}$ engine block presents some significant advantages with respect to cost, energy savings, and $\mathrm{CO}_{2}$ emissions.

Manufacturing process efficiency can obviously have a great impact on the energy consumption during that life-cycle phase of the vehicle. Salonitis and Ball [5] highlighted the importance of energy efficiency for both manufacturing processes and systems. One of the most energy-consuming manufacturing processes is casting (when considering all sub-processes such as melting, holding, finishing), and a lot of research is undertaken on how to improve its energy efficiency [6-10]. The casting process is used in the automotive sector for the manufacturing of a number of components both in the powertrain and in the body in white (BIW). A couple of attempts were also reported on the use of different materials for the casting of automotive components [11,12].

The objective of the present investigation is to establish a methodology for the environmental impact assessment of substitution of materials in the automotive sector so as to improve the current decision-making practices in the automotive sector. The discussion is on whether $\mathrm{Al}$ alloys are a better option than cast iron (CI), when the total energy burden is considered (and not only the tailpipe emissions). For assessing the energy required, an extensive literature review was undertaken, and over 100 experts from the automotive supply chain, such as original equipment manufacturers (OEMs), engine design consultancy firms, foundries, mining companies, primary alloy producers, and recycling companies, as well as machining, heat treatment, and impregnation companies, were contacted. The case study selected was the engine block, as it is the single heaviest component in most passenger cars.

\section{Methodology: Assessment Approach}

Focusing only on the use phase, or only on the manufacturing phase for the assessment of the overall environmental impact of a product does not allow for a full understanding of the whole picture. The "cradle-to-grave" approach aims to include the energy consumption that occurs due to resource extraction and processing, component and product assembly, use, and end-of-life processing of a vehicle (Figure 1). The evaluation of the overall impacts that a product has on the environment through all of these life-cycle stages would give a complete picture of the lightweighting shift validity.

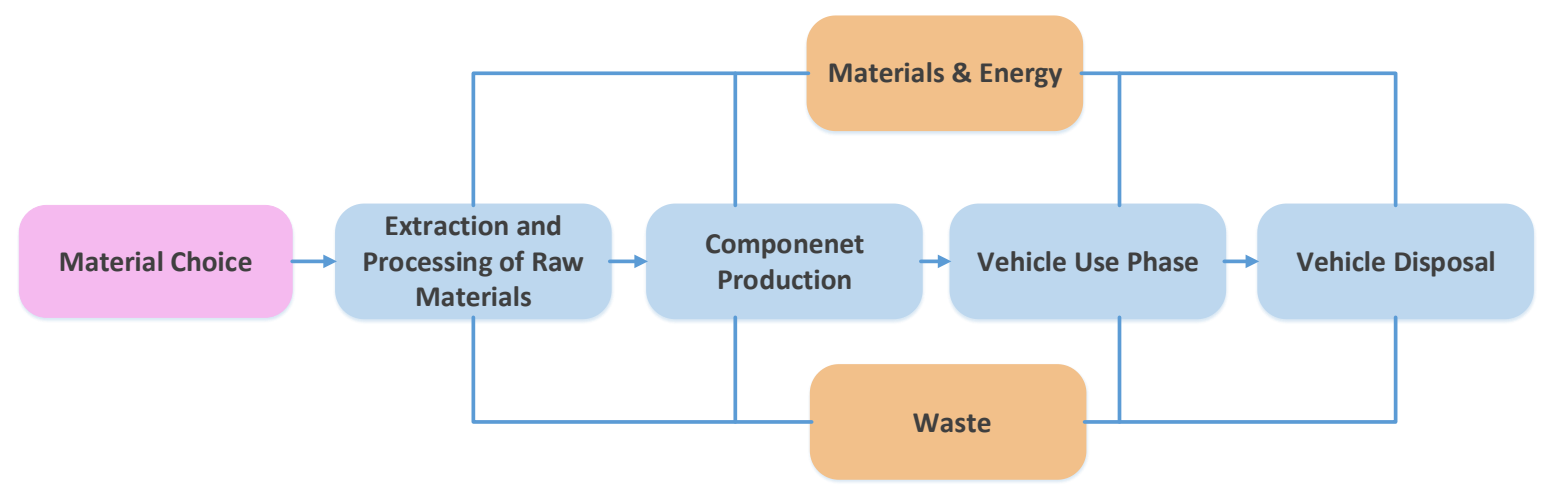

Figure 1. "Cradle-to-grave" approach.

For assessing the energy required and the $\mathrm{CO}_{2}$ emissions in each stage of the life cycle, an extensive literature review was undertaken. The present study focused on all the processes, from cradle to 
grave, in the production of passenger vehicle engine blocks, such as mining, smelting and electrolysis, melting, holding, casting, fettling, heat treatment, machining, impregnation, and recycling.

\section{Embodied Energy in Materials Due to Primary Production}

The starting point is the calculation of the primary production energy for each type of material. For the calculation of embodied energy, the methodology proposed by Brimacombe et al. [13] is used.

\subsection{Primary Aluminum Production}

The production of primary aluminum requires a number of steps. Allwood and Cullen [14] suggested that, for primary aluminum, the energy required is of the order of $170 \mathrm{GJ} / \mathrm{ton}$. The literature review indicated that energy ranges from 50 to $100 \mathrm{GJ} / \mathrm{ton}$. Due to the ambiguity in these figures, the energy requirements were calculated theoretically; Figure 2 shows that, for one ton of primary aluminum, $98 \mathrm{GJ}$ of energy is required. In the paragraphs below, the calculation of these figures is explained.

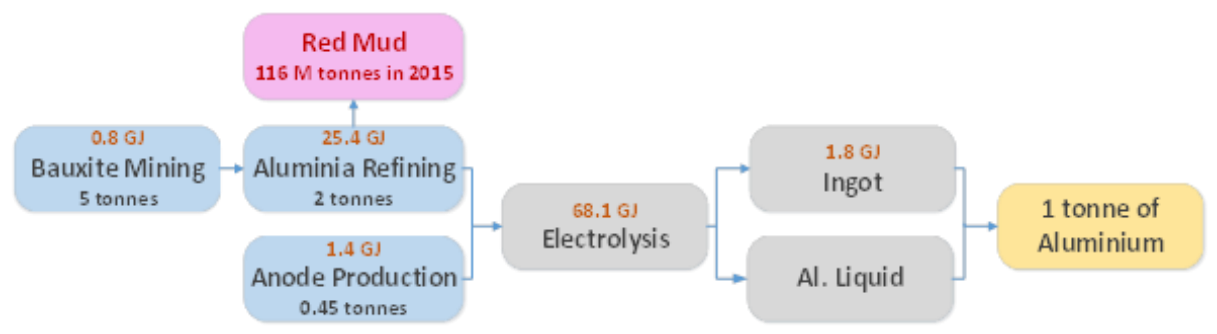

Figure 2. Primary aluminum production steps with associated energy content for producing one ton of material.

Primary production of aluminum starts with the mining of dry bauxite, which requires $0.17 \pm 0.08 \mathrm{GJ} / \mathrm{t}$. This figure was calculated after reviewing a number of reported energy figures in the literature review as listed in Table 1.

Table 1. Bauxite mining energy per ton of bauxite.

\begin{tabular}{cc}
\hline Source & Energy $(G J / t)$ \\
\hline$[15]$ & 0.145 \\
{$[16]$} & 0.150 \\
{$[17]$} & 0.150 \\
{$[18]$} & 0.153 \\
{$[19]$} & 0.188 \\
{$[20]$} & 0.210 \\
\hline
\end{tabular}

Alumina is refined from bauxite through the Bayer process, where the main steps are digestion, clarification, precipitation, and calcination [21]. Firstly, dry bauxite is crushed in large mills and blended with liquor to form slurry. Then, lime and caustic soda are added, mixed, and poured into the digester, where a solution of hot caustic soda dissolves the alumina. During the digestion, impurities drop to the bottom and form a solid waste residue called red mud. In order to separate the alumina from the red mud, the mix is moved to clarification. By cooling, aluminum hydroxide is precipitated from the caustic soda and then washed. The last step is calcination, where the water content in hydroxide is removed, and the alumina white powder is produced [22]. The energy consumption in this process varies in a range where the calculated average is $13.2 \pm 6.4 \mathrm{GJ} / \mathrm{t}$ of alumina (Table 2). 
Table 2. Alumina refining energy per ton of alumina.

\begin{tabular}{cc}
\hline Source & Energy $(\mathbf{G J} / \mathbf{t})$ \\
\hline$[19]$ & 13.17 \\
{$[17]$} & 12.52 \\
{$[23]$} & 10.65 \\
{$[15]$} & 12.77 \\
{$[16]$} & 14.20 \\
{$[18]$} & 17.90 \\
{$[24]$} & 15.00 \\
{$[25]$} & 13.80 \\
{$[23]$} & 10.95 \\
{$[26]$} & 10.65 \\
{$[20]$} & 13.82 \\
\hline
\end{tabular}

Red mud is highly alkaline ( $\mathrm{pH}=13)$, having great environmental impact; thus, it is very difficult to dispose of. It represents a major problem in the primary aluminum production. Red mud disposal covers vast areas which consequently cannot be built or farmed on, even after red mud is dried after several years. The most common ways to dispose of it is by land storage in the form of lagoons, dry stacking, or dry cake [23]. Two or more tons of red mud is produced for every ton of aluminum.

The key process for producing $\mathrm{Al}$ is electrolysis. Alumina is dissolved in a molten cryolite to decrease the melting point of alumina. The process, known as the Hall-Heroult process after the inventors, passes an electric current through the molten alumina to dissociate it into aluminum and oxygen. The oxygen reacts with the carbon anode to produce $\mathrm{CO}_{2}$, whilst molten aluminum remains and is tapped off periodically into teapot ladles [22]. In terms of process consumables, carbon anodes are used. A mix of calcined petroleum coke, recycled anodes butts, and coal are baked at $1150{ }^{\circ} \mathrm{C}$ to produce anodes, consuming 3.1 GJ per ton of anode. Depending on the anode use, the produced $\mathrm{Al}$ can be differentiated. The two main technologies are prebake (anodes are baked in ovens and then consumed in the electrolysis cells) and Soderberg (anodes are baked directly in the electrolysis cell) [23]. Furthermore, the carbon anode is totally consumed in Soderberg technologies, while, in prebake technologies, $80 \%$ is consumed and the other $20 \%$ is used again in the anode production process. In Europe, most of the electrolysis facilities use prebake technology with the exception of two Soderberg smelters placed in Spain. By calculating the average from the range of energy consumptions required for electrolysis, the process consumes approximately $54.4 \pm 4.5 \mathrm{GJ} / \mathrm{t}$ of produced $\mathrm{Al}$ (Table 3 ). Also, if $80 \%$ of the total amount of carbon anode is converted into carbon dioxide, an extra energy of $14 \mathrm{GJ} / \mathrm{t}$ aluminum is added to the process [26], ending up with a total energy consumption of $68 \mathrm{GJ} / \mathrm{t}$ aluminum in the electrolysis process.

Table 3. Electrolysis energy per ton of aluminum.

\begin{tabular}{cc}
\hline Sources & Energy (GJ/t) \\
\hline$[27]$ & 56 \\
{$[24]$} & 52 \\
{$[28]$} & 66 \\
{$[21]$} & 54 \\
{$[29]$} & 53 \\
{$[16]$} & 55 \\
{$[20]$} & 47 \\
{$[23](95 \%$ prebaked and 5\% Soderberg) } & 53.6 \\
{$[23](89 \%$ prebaked and 11\% Soderberg) } & 55.0 \\
{$[24]$} & 50 \\
{$[18]$} & 55 \\
{$[26]$} & 56 \\
\hline
\end{tabular}


Afterward, the molten aluminum is poured into molds to solidify in different shapes, which are shipped as ingots. In some cases, liquid aluminum is transported in insulated ladles by road depending on the proximity of the foundry [18]. The average energy consumption for ingot casting from the range collected from the literature review is $1.81 \pm 0.17 \mathrm{GJ}$ per ton of aluminum (Table 4). Finally, by adding up all the energy consumed in all the different processes, the production of one ton of primary aluminum requires $98 \mathrm{GJ}$.

Table 4. Cast ingot energy per ton of aluminum.

\begin{tabular}{cc}
\hline Sources & Energy (GJ/t) \\
\hline$[26]$ & 2.00 \\
{$[18]$} & 1.77 \\
{$[20]$} & 1.67 \\
\hline
\end{tabular}

\subsection{Pig Iron Production}

Similarly, for primary iron/steel, the energy required for the production of pig iron, according to the literature review, ranges from 20 to $40 \mathrm{GJ} /$ ton. Revisiting the process and calculating the energy per phases theoretically indicated that the energy content of one ton of primary iron is 17 GJ (Figure 3). In the paragraphs below, the calculation of these figures is explained.

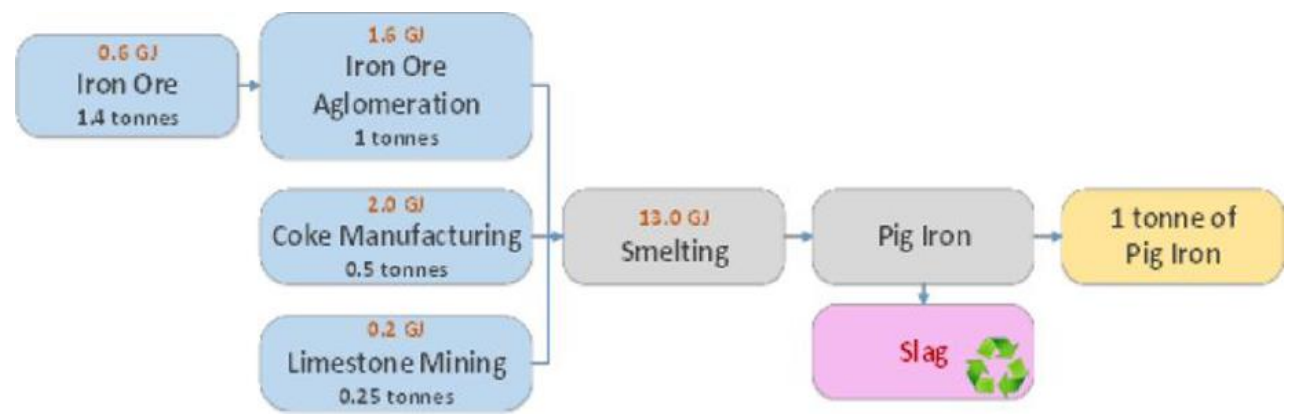

Figure 3. Primary iron production steps with associated energy content for producing one ton of material.

According to Moll et al. [30], the main raw material in pig iron production is iron ore, consuming an average energy of $0.44 \pm 0.2 \mathrm{GJ} / \mathrm{t}$ of iron ore mined (Table 5). Fine iron ores are converted into lump ores before charging into the blast furnace, in a process known as iron ore agglomeration. There are two different processes of agglomeration which are used in industry: sintering and pelletizing. Sintering plants are usually located near the blast furnace site, while pelletizing plants are situated near the mines [31]. From the range of data collected, the average energy required for this process is $1.59 \pm 0.36 \mathrm{GJ} / \mathrm{t}$ of iron agglomerate (Table 6).

Table 5. Iron ore mining and concentration energy per ton of iron ore.

\begin{tabular}{cc}
\hline Sources & Energy (GJ/t) \\
\hline$[32]$ & 0.153 \\
{$[33]$} & 0.142 \\
{$[30]$} & 0.177 \\
{$[27]$} & 0.956 \\
{$[34]$} & 0.750 \\
\hline
\end{tabular}


Table 6. Iron ore agglomeration per ton of iron ore agglomerated.

\begin{tabular}{cc}
\hline Sources & Energy (GJ/t) \\
\hline$[35]$ & 1.70 \\
{$[33]$} & 1.50 \\
{$[27]$} & 1.37 \\
[36] & 1.60 \\
[30] (pelletizing) & 1.33 \\
[30] (sintering) & 1.55 \\
[37] (pelletizing) & 0.82 \\
[37] (sintering) & 1.54 \\
[38] (sintering) & 2.25 \\
[34] (sintering) & 1.75 \\
[31] (pelletizing) & 2.10 \\
[31] (sintering) & 1.60 \\
\hline
\end{tabular}

Coal is converted at high temperatures to produce coke, which will provide permeability, heat, and gases which are required to reduce and melt the iron ore, pellets, and sinter [39]. The energy consumed to produce one ton of coke is approximately $3.98 \pm 1.1 \mathrm{GJ}$ (Table 7). In some countries like Brazil, charcoal is commonly used in the production of pig iron instead of coke.

Table 7. Coke manufacturing energy per ton of coke.

\begin{tabular}{ccc}
\hline Sources & Specific Country & Energy (GJ/t) \\
\hline$[27]$ & & 2.19 \\
{$[40]$} & & 3.70 \\
\hline & Germany 2003 & 3.70 \\
\cline { 2 - 3 }$[34]$ & Japan 2002 & 3.50 \\
\cline { 2 - 3 } & China 2004 & 4.20 \\
\hline$[35]$ & & 4.30 \\
{$[37]$} & & 4.45 \\
{$[22]$} & & 3.59 \\
{$[36]$} & & 5.80 \\
{$[38]$} & & 2.40 \\
{$[31]$} & & 6.00 \\
\hline
\end{tabular}

Finally, limestone is added in order to remove the impurities [33]. Similar to iron ore, limestone also has to be extracted from the earth, in a process that consumes close to $0.9 \pm 0.5 \mathrm{GJ}$ per ton (Table 8 ).

Table 8. Energy consumption per ton of limestone.

\begin{tabular}{cc}
\hline Sources & Energy (GJ/t) \\
\hline$[41]$ & 0.964 \\
{$[27]$} & 0.848 \\
\hline
\end{tabular}

The iron ore (lump, sinter, and/or pellets), along with additives such as limestone and reducing agents (coke), is put into the blast furnace in order to smelt. Then, a hot air blast is injected into the blast furnace. The limestone is melted to remove the sulfur and other impurities, originating a residue known as slag. This process, known as smelting, is the most energy-consuming in the production of pig iron, accounting for $13 \mathrm{GJ}$ (Table 9) of the total $17.4 \mathrm{GJ}$ per ton of pig iron. 
Table 9. Energy consumption per ton of limestone.

\begin{tabular}{ccc}
\hline Sources & Specifics & Energy (GJ/t) \\
\hline$[22]$ & & 16.90 \\
{$[38]$} & & $13.6-16.2$ \\
{$[42]$} & Blast furnace & 12.3 \\
{$[40]$} & Blast furnace & 10.4 \\
{$[27]$} & Raw iron manufacturing & 12.8 \\
{$[31]$} & Blast furnace & $13-14.1$ \\
{$[43]$} & Blast furnace & $12.7-18.6$ \\
{$[44]$} & & 12.0 \\
{$[34]$} & blast furnace & 10.4 \\
{$[45]$} & & 12.2 \\
{$[36]$} & blast furnace & 10.4 \\
{$[37]$} & & 13.63 \\
\hline
\end{tabular}

\subsection{Outcome}

In Figure 4, the various stages and their energy consumption for the production of one ton of pig iron and primary aluminum are shown. The difference in the total energy consumed to produce one ton of primary aluminum when compared to the production of the same amount of pig iron sums up to roughly $80 \mathrm{GJ}$.

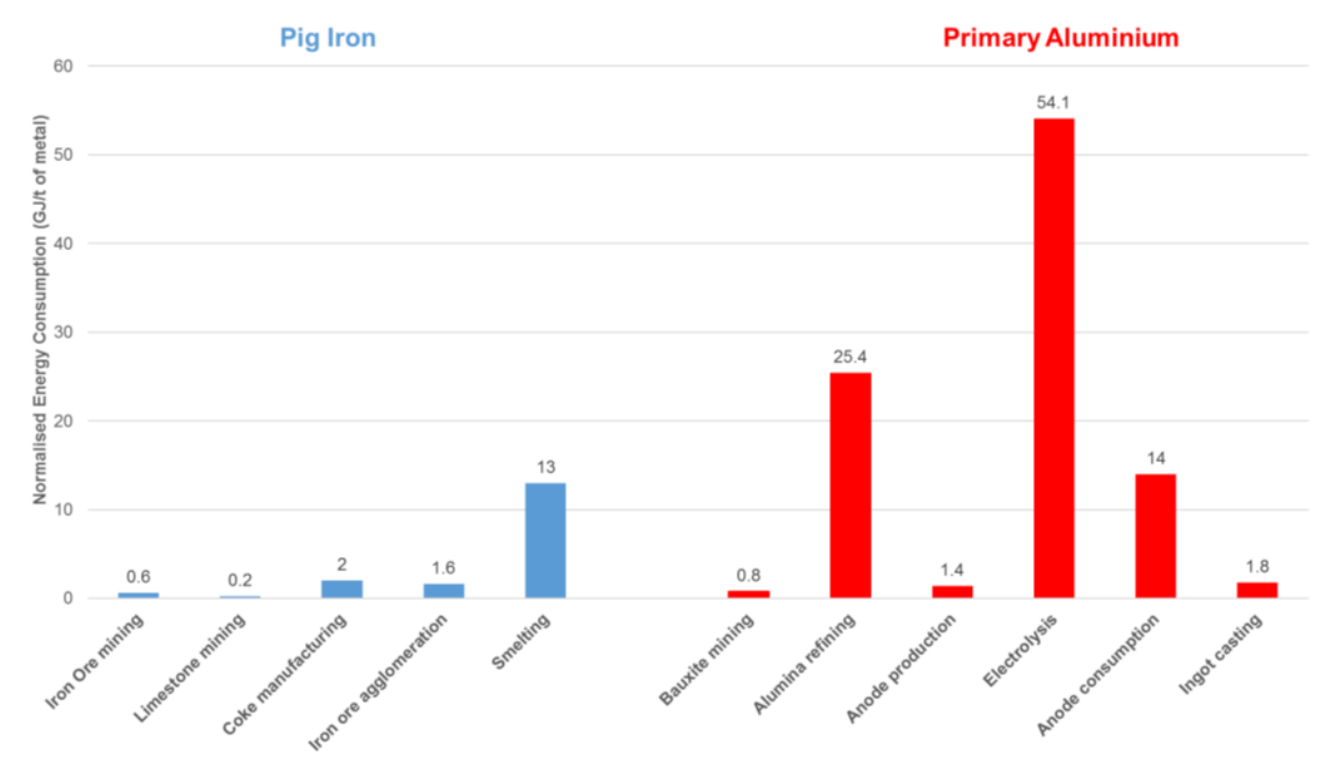

Figure 4. Energy consumption for the production of pig iron and primary aluminum.

Furthermore, red mud is a by-product of the primary aluminum production at a rate of two tons per ton of aluminum (120 million tons per year) and, at this moment, there are no solutions for it. On the other hand, the slag from the smelting process is easily recycled into road and cement making. Finally, the electrolysis of alumina consumes four times more energy than the whole production of pig iron.

\section{Case Study: Engine Block}

The heaviest single component in a passenger vehicle is the cylinder block. Over the last 10 years, the most significant transformation in engines was the capacity to provide more power with a lower displacement. This is a result of one of the most significant engine trends: downsizing. Comparing 2001 with 2013, engine power increased 20\% while engine displacement decreased by $10 \%$ [46]. Furthermore, the top-selling vehicle models worldwide follow this trend. According to Reference [46], the engine 
displacement of the most sold vehicles is between 0.8 and $2.0 \mathrm{~L}$, except for the United States of America (USA) and Canada, where engines with more power and displacement are highly valued.

The four-cylinder blocks were selected as a case study in the present study, as they represent approximately $71 \%$ of the total blocks manufactured worldwide [47]. For the reasons mentioned in the previous paragraph, the present investigation focuses on in-line four-cylinder 1.6-L engine blocks. These can be found in both diesel and petrol versions and in both $\mathrm{CI}$ and Al-alloy materials. Al-alloy engine blocks are lighter than $\mathrm{CI}$ engine blocks as illustrated in Figure 5. However, due to the fact that $\mathrm{CI}$ is stronger than $\mathrm{Al}$ alloys, $\mathrm{Al}$-alloy engine blocks need thicker walls between cylinder bores, making them longer. As a result, the volume of CI required is considerably less, being in the region of $55 \%$ of that of the equivalent $\mathrm{Al}$-alloy block, and $\mathrm{CI}$ engines are considerably more compact. As illustrated in Figure 5, the weight differentials between the petrol and diesel engines made of $\mathrm{Al}$ alloy and $\mathrm{CI}$ are 9 and $11 \mathrm{~kg}$, respectively. However, more compact engines lead to an even smaller weight difference in the fully assembled engine, as a result of smaller ancillary components. Thus, our calculations are based on an on-the-road weight differential for the engine of $7 \mathrm{~kg}$ and $9 \mathrm{~kg}$ for petrol and diesel, respectively, which was substantiated by a number of design consultancy firms and OEMs.

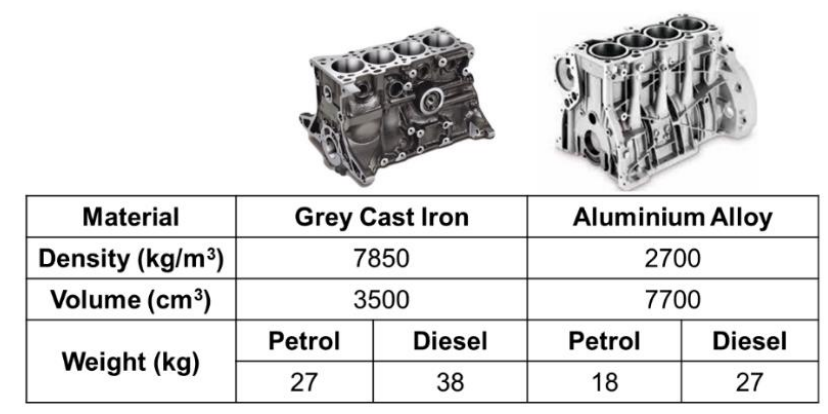

Figure 5. Weight difference between cast iron and aluminum-alloy engine blocks according to the fuel consumed by the vehicle for 1.6-L engines.

In Figures 6 and 7, the process flow for manufacturing the engine blocks from $\mathrm{CI}$ and $\mathrm{Al}$ alloys, respectively, is presented. The key difference between the two process flows is the need for heat treatment in the case of Al-alloy engine blocks and the use of liners.

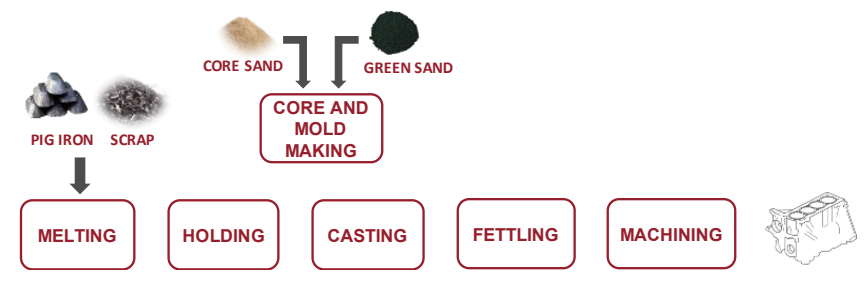

Figure 6. Process flow for cast iron (CI) engine block manufacturing.

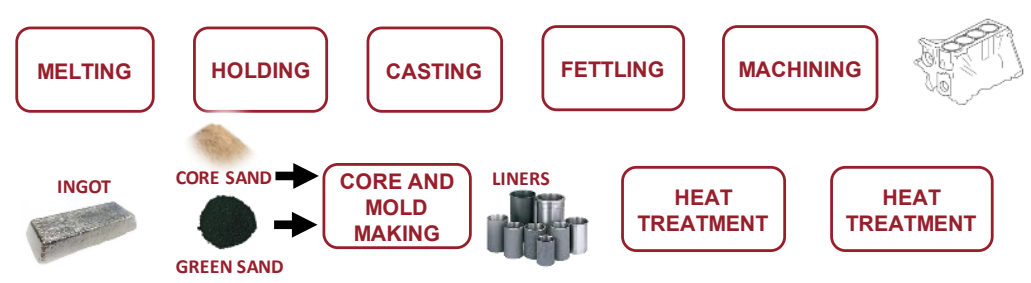

Figure 7. Process flow for Al-alloy engine block manufacturing.

\subsection{Engine Blocks}

Producing engine blocks from cast iron requires casting to a near net shape and machining to the exact dimensions. For collecting the required data (material use and energy consumption), three casting 
foundries were visited. These three foundries are responsible for the production of more than $60 \%$ of the world's cast-iron engine blocks.

\subsubsection{Melting Stage}

The casting temperatures for $\mathrm{CI}$ and $\mathrm{Al}$ vary around $1500^{\circ} \mathrm{C}$ and $730^{\circ} \mathrm{C}$, respectively. This normally occurs in a melting furnace which can differ from foundry to foundry and/or for different metals. Normally, two types of furnaces are used: cupola and induction. By a number of foundries, it was verified that they only use cupola furnaces to produce $\mathrm{CI}$ engine blocks. Cupola furnaces use coke as an energy source, and their thermal efficiency ranges between 20 and 30\%. The main inputs in these furnaces are pig iron (4.8\%), ferrosilicon $75 \% \mathrm{Si}(4 \%)$, and steel and/or CI scrap (91.2\%). Unrecoverable metal losses, mainly due to oxidation, are reported by foundries, to an average of $2 \%$. In total, three CI foundries were audited, and the energy per ton of liquid metal was measured to be $3.9 \pm 0.1 \mathrm{GJ}$ (Figure 8).

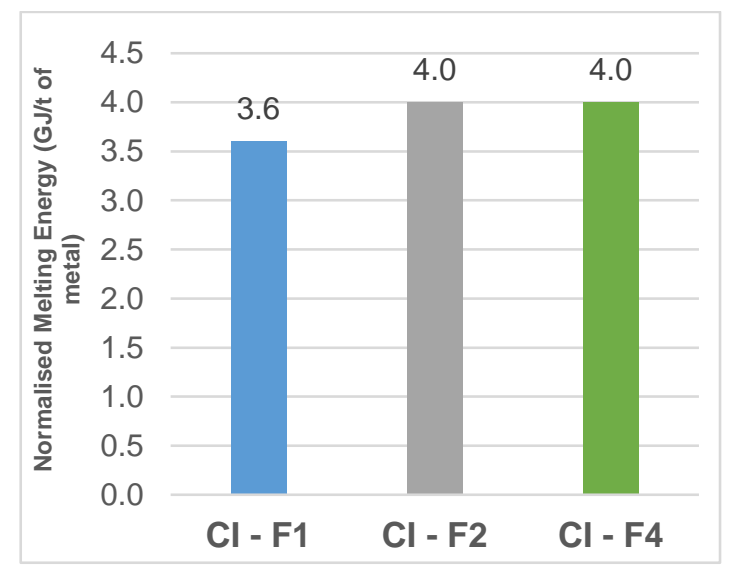

Figure 8. Melting energy per ton of liquid metal in three different cast-iron foundries.

\subsubsection{Holding Stage}

After melting, to keep the metal at casting temperature and with a consistent composition, it is transferred and kept in the holding furnace as a buffer due to different production rates. The energy per ton of liquid metal was measured to be $0.2 \pm 0.1 \mathrm{GJ}$ in two foundries (Figure 9). The holding furnaces in both foundries were electricity powered. One of the biggest factors in the energy consumption during the holding process is the holding time. This changes from foundry to foundry according to the production rate, casting method, and of course the type of metal. In the holding process, the foundries reported an unrecoverable metal loss of $2 \%$.

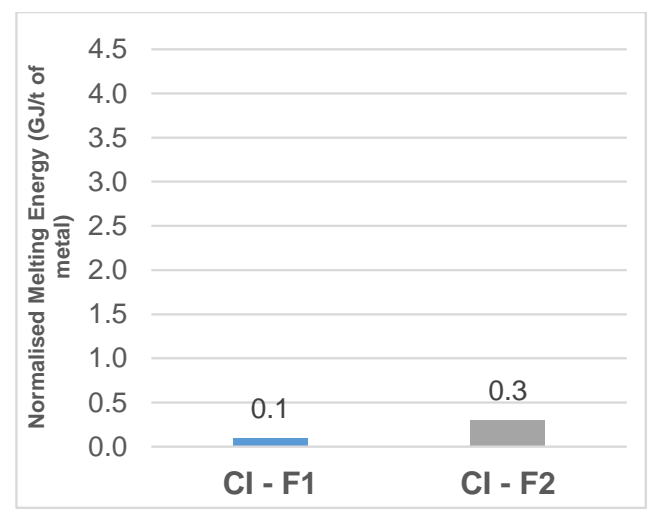

Figure 9. Holding energy per ton of liquid metal in two different cast-iron foundries. 


\subsubsection{Core- and Mold-Making Stage}

In engine block castings, cores are used to form the complex internal geometry of the block. Cores are made from silica sand using the cold box method, where a binder system is used to cure the sand and resin to form the core. The design of the core varies depending on the material to be casted, and, for CI engine blocks, the reported core weight is $42.6 \pm 4 \mathrm{~kg}$ (Figure 10a). The process of core-making also consumes a significant amount of energy, as the cores are normally coated and baked before use. Three foundries reported average energy needed for core-making to be $0.97 \pm 0.3 \mathrm{GJ}$ per ton of core sand (Figure 10b). In addition to the cores, a sand mold is used to form the outer limits of the casting. It is also used to support the core package, which together form the core package system. The weight of the sand mold, according to one of the foundries, is approximately $180 \mathrm{~kg}$. For the formation of the mold, machining is used that is reported to consume $0.16 \pm 0.2 \mathrm{GJ}$ (Figure 10c) per ton of green sand.

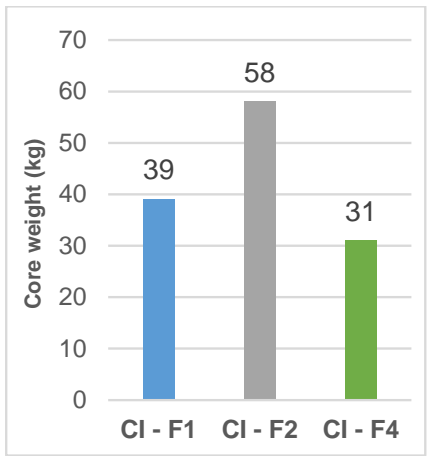

(a)

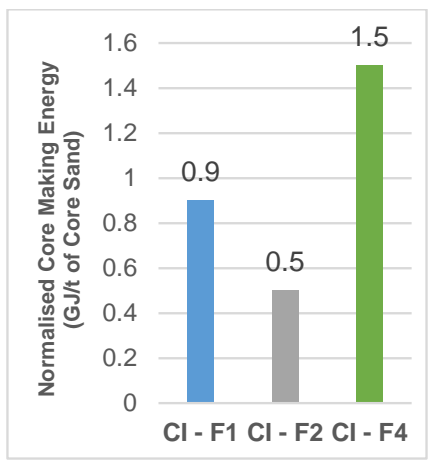

(b)

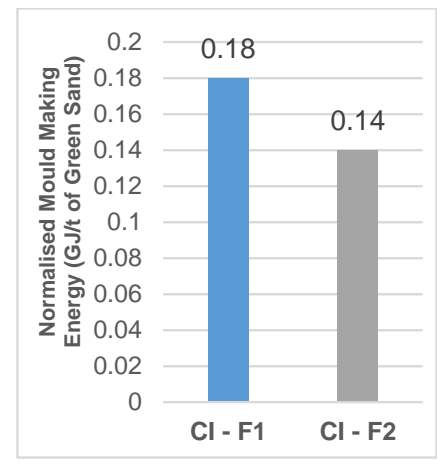

(c)

Figure 10. Mold- and core-making: (a) core weight, (b) core-making energy, and (c) mold-making energy.

\subsubsection{Casting Stage}

For the casting of CI into engine blocks, all visited foundries reported that only gravity sand casting is used, using green sand molds and a core package. In gravity sand casting, liquid metal is poured into a cavity that is formed by a monolithic sand mold, as explained previously. The pouring of the metal can be fully automated, semi-automated, or completely manual. Flow rates of the metal may vary from the beginning to the end of a casting campaign as the pouring ladle empties. Metal flow velocities should be adequate to avoid turbulence and achieve a good-quality casting. Sand castings have a low cooling rate because of the sand insulating mass surrounding the casting.

\subsubsection{Fettling Stage}

Following the casting process and the removal of the solid block from the sand mold, it has to be roughly machined to remove secondary cavities, risers, runners, and gates (also known as fettling). This excess material is usually re-melted. The mold yield reported from all three foundries was $75 \pm$ $1 \%$ (Figure 11a). The energy consumed during the process varies significantly per foundry, and the reported values range from 0.1 to $1.4 \mathrm{GJ}$ per ton of liquid metal (Figure 11b).

\subsubsection{Machining Stage}

Castings are produced volumetrically larger than required. Surfaces such as cylinder bores, deck faces, crankshaft bores, etc. are casted with an excess material of 2-3 mm that allows later dimensional corrections. A large number of holes must be drilled for oil circulation, bolts, etc. The main machining operations in an engine block are cubing, boring, drilling, and threading. Machining performance and, consequently, machining energy consumption may vary according to the machining parameters used. The energy can be significantly reduced by arranging for casting feeders to be 
located on areas which are to be machined. The approach used to quantify the energy requirements during machining is based on an analytical model provided by MAG Manufacturing Technology [48]. The model used is based on real machining energy measurements and has the capability to aggregate all the ancillary energy requirements (air, coolant supply, etc.) into each operation. Cycle times for each operation were obtained from machining outsourcing houses for two in-line four-cylinder blocks. The total energy consumption calculated for machining one cast-iron block is $61 \mathrm{MJ}$, i.e., $1.6 \mathrm{GJ} /$ ton of cast-iron block. Usually, $10 \mathrm{~kg}$ of material is removed, which represents $20 \%$ of the block.

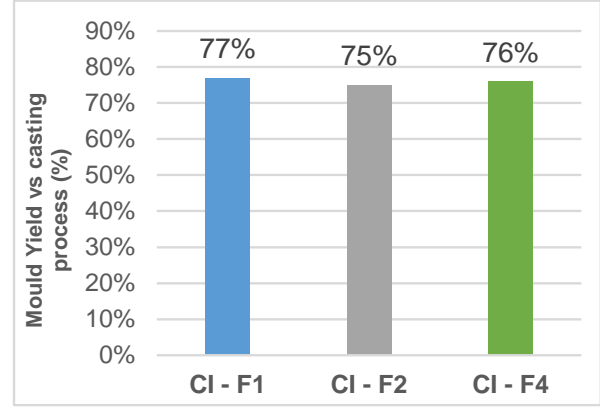

(a)

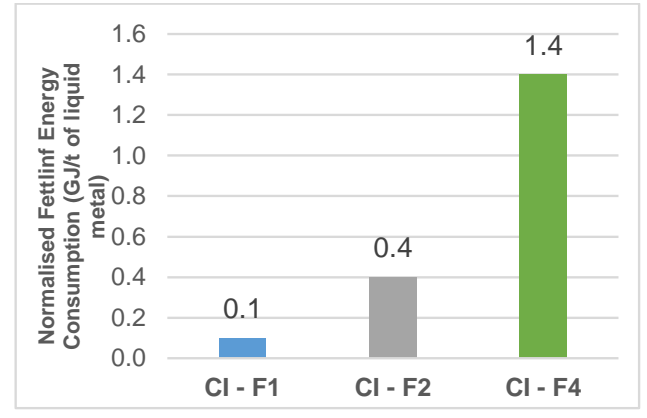

(b)

Figure 11. Fettling process: (a) mold yield in different casting processes; (b) fettling energy consumption.

\subsubsection{Ancillary Processes}

Miscellaneous energy is related to the facility operation and other ancillary processes like heating, lighting, etc. The energies included in each foundry for the miscellaneous processes vary widely. In the case of the three $\mathrm{CI}$ foundries, the reported energy ranged from 0.1 to $3.8 \mathrm{GJ}$ per ton of good casting.

\subsubsection{Inspection Stage}

Quality inspection is undertaken throughout the casting process. Foundries aim to minimize their internal rejection rate to increase their efficiency by applying strict internal inspection standards in order to not ship and transport bad product. CI foundries reported an average of $3 \%$ internal scrap and $0.5 \%$ external scrap. Internal scraped CI blocks are re-melted directly.

\subsubsection{Material Recycling}

In all foundries, material is recycled. The furnace charge that foundries are using for engine block manufacturing comes from two different sources-external recycling (new scrap, old scrap, turnings, and dross) and in-house recycling (Figure 12). According to foundry practices, the ratio between the two differs. The dominant production route for steel made from scrap is electric arc furnace, while the energy needed is equal to on average $7 \mathrm{GJ} /$ ton (Table 10). The most common route for primary steel production is basic oxygen furnace that converts pig iron into steel. The energy for this step on average is equal to $0.8 \mathrm{GJ} /$ ton. Together with pig iron production energy, a full steelmaking process is equal to 18.2 GJ per ton.

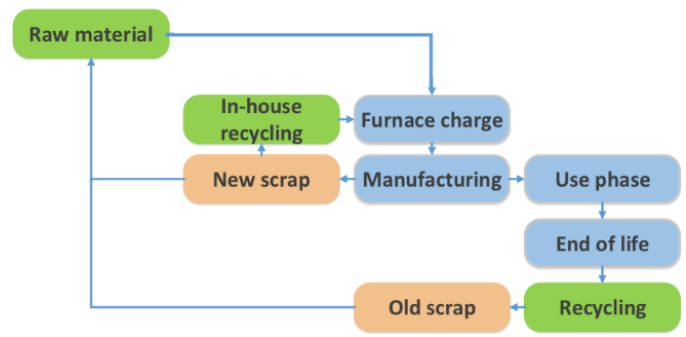

Figure 12. Material flow diagram of the recycling. 
Table 10. Energy for steel recycling with electric arc furnace.

\begin{tabular}{cc}
\hline Source & Energy $(\mathrm{GJ} / \mathbf{t})$ \\
\hline World Steel Association (2015) & $5.3-8.7$ \\
{$[49]$} & $6-15$ \\
{$[50]$} & $8.1-9.0$ \\
{$[13]$} & 10 \\
{$[22]$} & 5.5 \\
{$[43]$} & 5.3 \\
{$[44]$} & 5.5 \\
\hline
\end{tabular}

Because the history of the scrap that is used as a furnace charge is not known [13], it is necessary to consider all the stages that the material might go through, from initial manufacture to final disposal. Based on the number of product cycles, the embodied energy in the material can be estimated by calculation. The total energy content for the chosen number of cycles can be calculated as follows [13]:

$$
X=\left(X_{p r}-X_{r e}\right)\left[\frac{(1-r)}{\left(1-r^{n}\right)}\right]+X_{r e}
$$

According to Equation (2), the energy burden for multiple recycling, where the material is recycled indefinitely, can be obtained by calculating the following [13]:

$$
X=X_{p r}-r\left(X_{p r}-X_{r e}\right)
$$

where $X_{p r}$ stands for energy for manufacturing one ton of material via the primary route, $X_{r e}$ is the energy for manufacturing one ton of material via the recycling route, $r$ is the overall recycling efficiency over one life cycle $(r=R R \cdot Y), R R$ is the scrap recovery rate $(\%)$, and $Y$ stands for the efficiency of the recycling process (\%). Figure 13 represents the embodied energy for steel scrap after recycling. For the electric arc furnace (EAF) route and steel scrap processing, the average overall recycling efficiency $(r)$ includes the furnace yield and the efficiency of recovering the steel at the end-of-life $(r=0.89)$ [13].

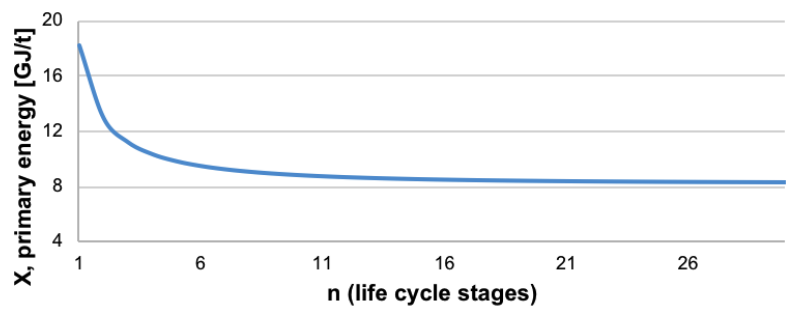

Figure 13. Steel scrap embodied energy $(X=8.2)$ for electric arc furnace $(E A F)$ recycling route.

However, the above analysis considers only the once-through product system. To undergo a full energy analysis, the influence of recycling and reusing material in the casting process should also be considered [14]. As a result, the multiple life-cycle method needs to be adopted. The residue metal that can be again re-melted comes from fettling (in the form of runners and feeders), rarely machining (swarf), and internal inspection. Apart from metal, other process materials like core sand and green sand can also be recycled (via thermomechanical or thermal sand reclamation) or reused [51]. The embodied energies for cast-iron, core sand after reclamation and green sand are illustrated in Figure $14 a, b, c$ respectively.

The alloying and treatment materials need to be considered as well. For CI, ferrosilicon is added to enhance the grain structure and metallurgy of the finished component. The energy content to produce one ton of ferrosilicon master alloy is just over $30 \mathrm{GJ}$. However, the addition rate into the iron is such that this contributes $1.6 \mathrm{GJ} /$ ton of $\mathrm{CI}$ engine blocks. 
Figure 15 shows the Sankey diagram representation of the energy and materials flows. Using this, the largest areas of energy input, recycling loops, and material losses are shown.

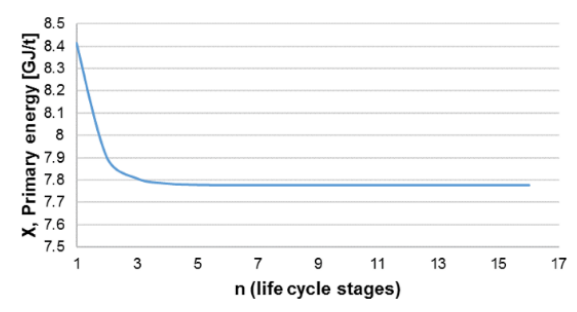

(a)

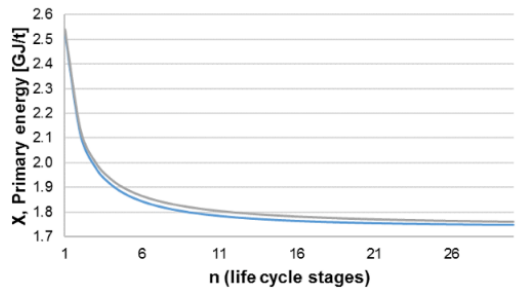

(b)

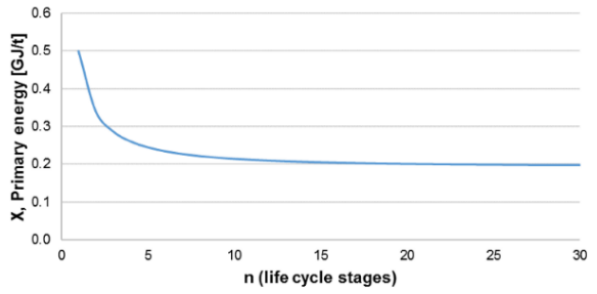

(c)

Figure 14. (a) Energy embodied in metal collected from the production stage and re-melted in-house in the cast-iron foundries (assumed $2 \%$ of the embodied energy for pig iron addition), (b) energy embodied in core sand after reclamation process, and (c) energy embodied in green sand for its multiple reuse.

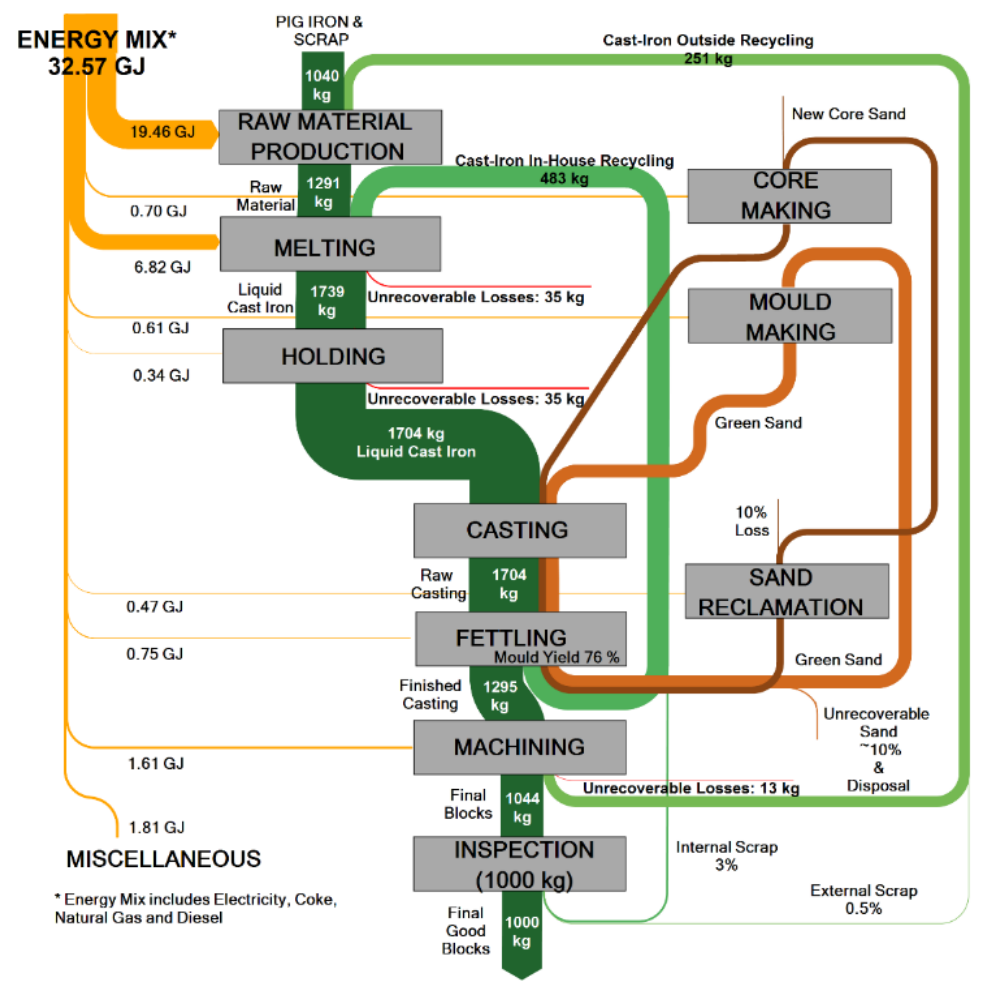

Figure 15. Energy and material flow in CI sand casting, showing that $1000 \mathrm{~kg}$ of good castings require the melting of $1739 \mathrm{~kg}$ of CI and $32.57 \mathrm{GJ}$.

\subsection{Al-Alloy Engine Blocks}

Figure 7 shows the process flow for Al-alloy engine block manufacturing. Compared to $\mathrm{CI}$ engine blocks, the process is slightly more complicated, as there is need for the use of liners as explained later on, as well as heat treatment of the cast components. Furthermore, the casting processes to 
be used vary from company to company. Three different casting processes can be identified that are widely used for the manufacturing, namely high-pressure die casting (HPDC), low-pressure die casting (LPDC), and low-pressure sand casting (LPSC; also known as the Cosworth process). Overall, $70 \%$ of aluminum-alloy engine blocks are casted by HPDC, while the other $30 \%$ are casted through a combination of the other methods [23].

The LPDC process consists of a dosing furnace which is pressurized, forcing liquid aluminum to enter the mold from the bottom. The mold consists of steel dies combined with internal sand cores. The repeatable rising and falling of the metal through the delivery tube may introduce oxide layers which eventually are delivered to the casting. LPDC is used for medium to long series of casting runs, where better mechanical properties are required when compared to HPDC. In HPDC, the alloy is inserted into a cold chamber and a hydraulic piston squeezes the metal into a steel die mold at extremely high speed (up to $80 \mathrm{~m} / \mathrm{s}$ ) and pressure (3500 tons). No sand cores can withstand the high pressure; thus, the HPDC block designs are limited to open-deck blocks.

Similar to cast-iron green sand casting, aluminum gravity sand casting also uses core packages. In the LPSC (Cosworth process), the metal is usually pumped into the sand mold from the bottom by an electrical pump. The difference from LPDC is that the metal in the pump never drops back to the level of the metal and, consequently, the level of oxide generated is potentially lower than in a gravity system [52]. Data were collected from a number of foundries that employ such processes.

\subsubsection{Melting and Holding}

In Al-alloy engine block foundries, tower furnaces are most commonly used [6]. The unrecoverable metal losses are of the same order of magnitude as CI. The foundries contacted reported an average energy consumption of $6.5 \pm 3 \mathrm{GJ}$ per ton of liquid metal (Figure 16). With regard to the holding of the liquid metal, the holding time varies between foundries. In HPDC and LPDC, the holding time is around four hours, while for LPSC it is 13 hours because of the additional time required for refining of the metal. The foundry using the Cosworth process used holding as a refining step to allow unwanted trace elements to settle out of the liquid $\mathrm{Al}$ alloy and oxides to float to the surface. Figure 17 shows the holding energy in GJ per ton of liquid metal.

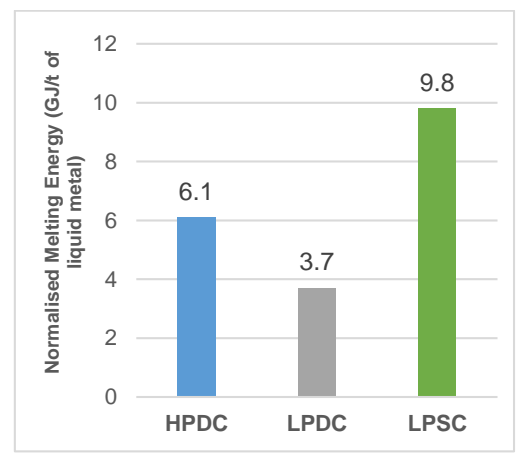

Figure 16. Melting energy per ton of liquid metal in three different Al foundries.

\subsubsection{Core- and Mold-Making}

The material and the process used for the core- and mold-making depend on the type of the casting process to be used. In LPSC foundries, cores are made from silica sand using the cold box method, where a binder system is used to cure the sand and resin to form the core. In HPDC, sand cores are not used due to the high-pressure injection of the metal which would destroy the cores. The core weight also varies for the different metals. The cores in cast iron sand casting are much heavier than in aluminum LPDC. This is because it includes the whole core package (cores + core shells). The energy required for making cores and the mold is quite similar with cast-iron sand casting (CISC), with the exception of when dies are used. 


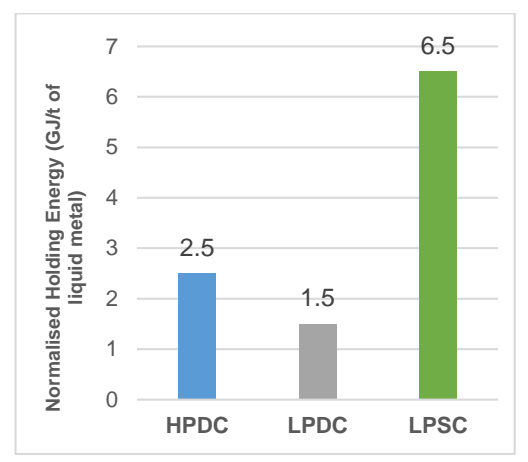

Figure 17. Holding energy per ton of liquid metal in three different $\mathrm{Al}$ foundries.

\subsubsection{Casting}

The four different casting processes were presented already. As per $\mathrm{CI}$, the energy consumed during the casting process is negligible with the exception of HPDC. In HPDC, automatic spray-up for lubrication and robotic casting removal after solidification also consume a lot of energy. The dies are usually monolithic and contain cooling and heating channels. Due to these extra energies in HPDC, a casting energy is accounted for in this casting method only (1.2 GJ per ton of casting). HPDC parts are near net shape, and less fettling and machining operations are required. Due to the nature of metal filling, HPDC castings are often non-heat-treatable but might go through a stress-relieving thermal cycle.

\subsubsection{Fettling}

Once the cast engine block is removed from the sand mold or the die, fettling is required as per the CI process as well. In the case of Al-alloy engine blocks, the reported mold yield is lower compared to $\mathrm{CI}$ and is approximately $65 \pm 2 \%$. The material removed from fettling aluminum-alloy engine blocks can be re-melted directly in the foundry or sold to an external recycling company to be transformed again into aluminum alloys. The second case relates to aluminum LPDC and, therefore, the calculations in this study, for LPSC, are based on outside recycling. The energy consumed during the fettling process was reported in all three foundries to be $0.6 \mathrm{GJ}$ per ton of liquid metal.

\subsubsection{Heat Treatment}

A key difference in the CI process flow is the need for heat treatment. Al-Si alloys used to produce Al-alloy engine blocks usually require $\mathrm{T} 6$ and $\mathrm{T} 7$ heat treatments which are used to improve both mechanical and wear properties [53]. Foundries also reported that T5 is the most common heat treatment process used in HPDC. The average energy consumption per casting can be calculated when temperature and holding times are known.

Considering a treatment efficiency of 100\%, the average energy consumption for heat treatments T6 and T7 can be calculated to be $3.2 \mathrm{GJ} /$ ton of finished casting. For T5, the average energy consumption is calculated to be $1.0 \mathrm{GJ} / \mathrm{t}$. For the case of engine block casting, $20 \%$ heat treatment efficiency is required; thus, the values considered were scaled accordingly.

\subsubsection{Impregnation}

Casting introduces porosities during the solidification of the liquid metal. Turbulent metal flow, gas entrapment, and metal shrinkage are the main factors that introduce voids in the casting. Porosity is more pronounced in aluminum-alloy castings because of its higher volumetric shrinkage and hydrogen content. The three main forms of porosity are full enclosed, blind, and through porosity. Such porosity could result in leaking under pressure, and would, thus, require the block to be scrapped. an impregnation process that introduces a polymer sealant in the pores and cracks of castings is used for 
this reason. The most commonly used impregnation process is the vacuum dry process. The castings are stashed into a basket and inserted in a series of chambers until a full impregnation cycle is achieved.

Around $90 \%$ of the energy in an impregnation cycle is consumed heating up the water at around $90{ }^{\circ} \mathrm{C}$, and the remaining $10 \%$ is used for circulation pumps, vacuum pumps, rotational mechanisms, and other ancillary systems. The energy involved in the process was ascertained to be around 7.2 MJ/engine block.

\subsubsection{Machining}

Using the MAG analytical model [48], the total energy consumption for machining is $51 \mathrm{MJ}$, of which $13 \mathrm{MJ}$ is for the initial machining of the cylinder liners.

\subsubsection{Liner Casting}

For the aluminum-alloy in-line four-cylinder blocks, for all casting processes, cast-iron cylinder liners are cast in the block. The wear and mechanical properties of hypoeutectic alloy sliding surfaces are not adequate to withstand the friction of the moving piston in the cylinder bore. Cast-in CI liners are used for the tribological system "cylinder-piston-piston ring". The liners are centrifugally cast and the induction pre-heated prior to casting at around $375{ }^{\circ} \mathrm{C}$ to achieve better bonding with the liquid $\mathrm{Al}$, ending up with a total energy of $188 \mathrm{MJ} /$ engine block. For the fettling of the solid casting system, the yield ratio is approximately $67 \%$ with a total energy consumption of $0.6 \mathrm{GJ}$ per ton of liquid metal.

\subsubsection{Material Recycling}

As with the $\mathrm{CI}$ foundries, $\mathrm{Al}$ foundries charge their furnaces with recycled material as well. The process is quite similar; however, Figure 12 needs to be updated in order to include secondary smelter and the production of ingots. Figure 18 illustrates the common processes for the material flow of the recycling model for the case of Al alloys.

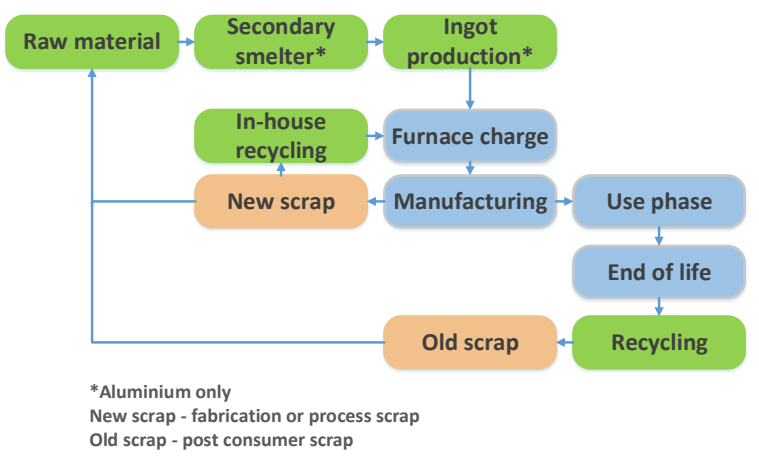

Figure 18. Material flow diagram of the recycling.

Al-alloy engine blocks are usually made from secondary ingot. The alloy used is A383 or A380 for LPDC and HPDC, and A319 for LPSC. The process of recycling Al scrap to form the alloys is by refining, a process that uses a combination of rotary and reverberatory furnaces [54]. The recycled $\mathrm{Al}$ can have similar properties to primary Al. However, in a course of multiple recycling, more and more alloying elements are introduced into the metal cycle. Secondary alloys have relatively high levels of impurities, especially iron, which is detrimental to many properties. The multiple life-cycle method is, thus, used (as in the $\mathrm{CI}$ recycling) for calculating an average energy consumption.

Figures 19-21 present the Sankey diagrams for the LPSC, LPDC, and HPDC cases, respectively. 


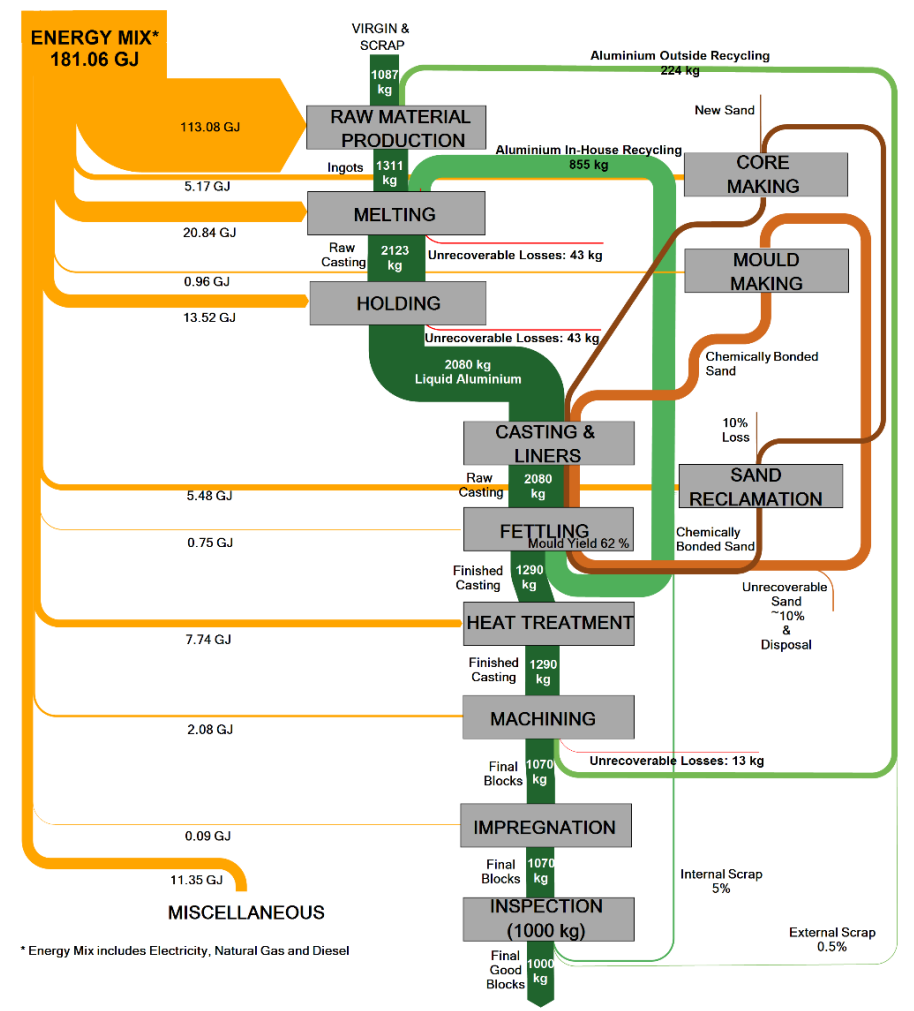

Figure 19. Energy and material flow in low-pressure sand casting (LPSC), showing that $1000 \mathrm{~kg}$ of good castings require the melting of $2123 \mathrm{~kg}$ of $\mathrm{Al}$ and $181.06 \mathrm{GJ}$.

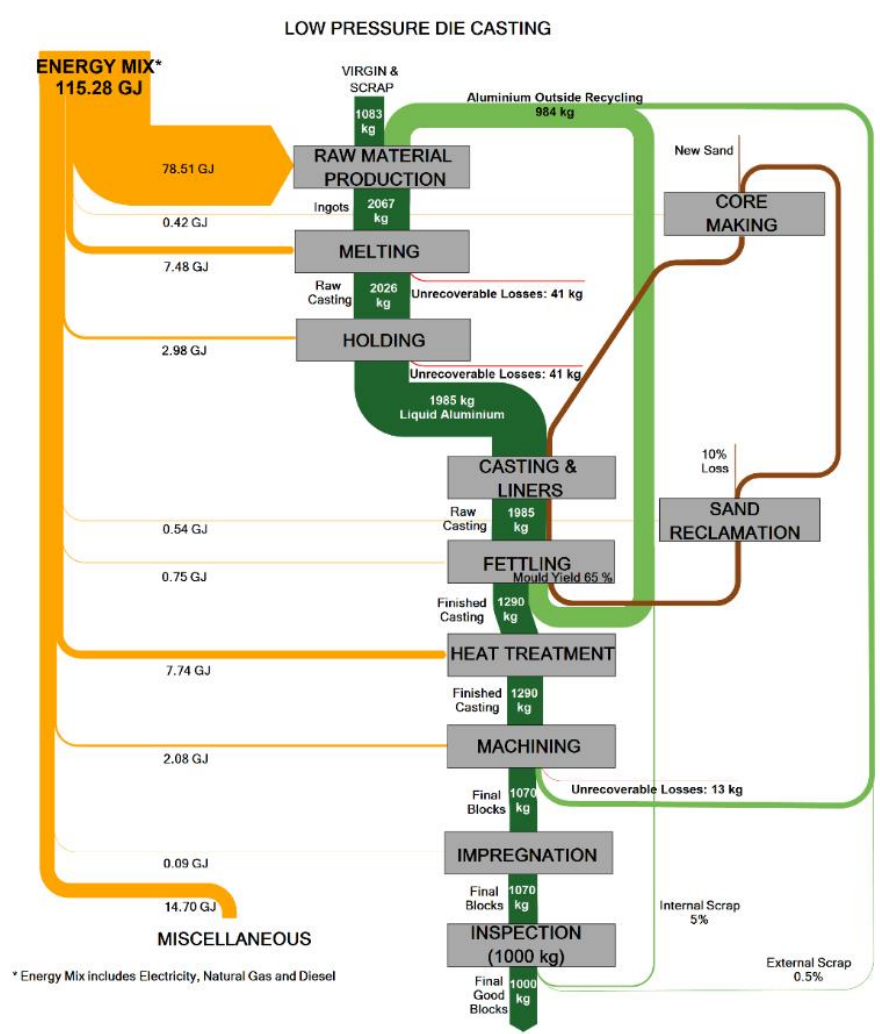

Figure 20. Energy and material flow in low-pressure die casting (LPDC), showing that $1000 \mathrm{~kg}$ of good castings require the melting of $2067 \mathrm{~kg}$ of $\mathrm{Al}$ and $115.28 \mathrm{GJ}$. 


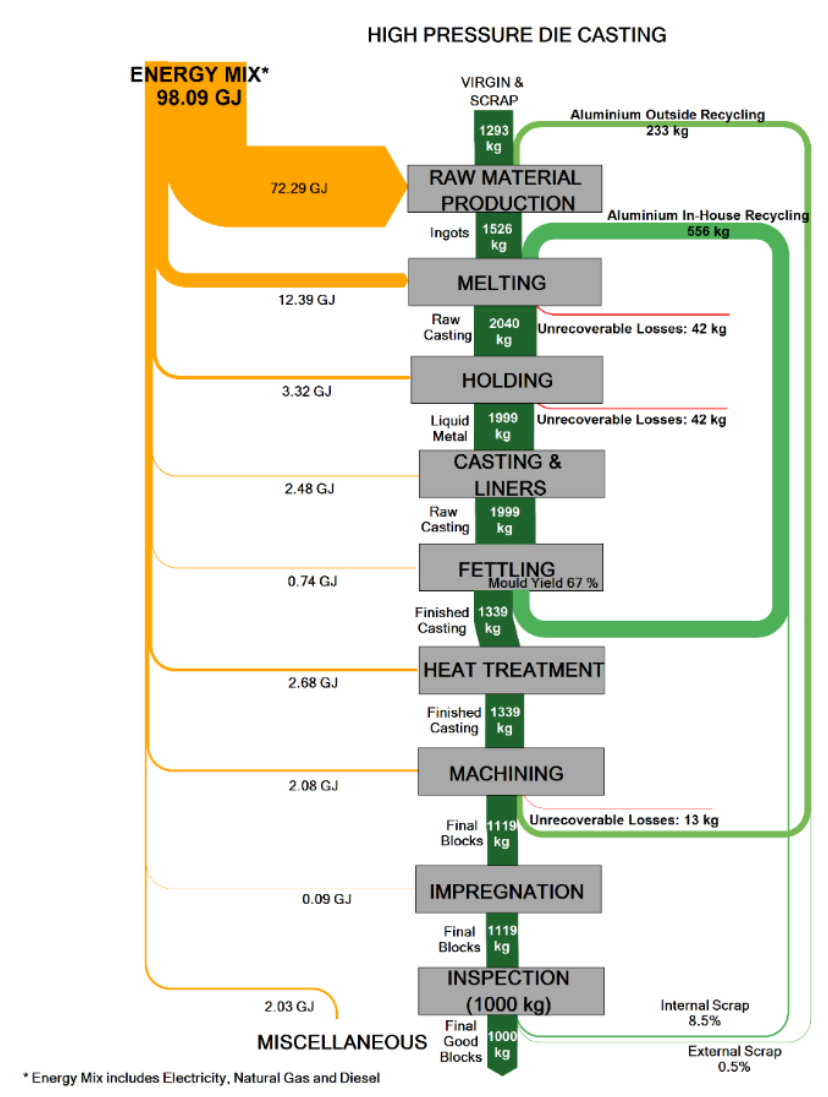

Figure 21. Energy and material flow in high-pressure sand casting (HPDC), showing that $1000 \mathrm{~kg}$ of good castings require the melting of $2040 \mathrm{~kg}$ of $\mathrm{Al}$ and $98.09 \mathrm{GJ}$.

\section{The Answer to the Dilemma between Al Alloys and CI}

Figure 22 shows the energy breakdown in each material source and indicates that ingot and external scrap represent the highest embodied energy of the charge and feedstock for Al-alloy and CI engine blocks. Figure 23 demonstrates the process energy breakdown for each casting. It is obvious that the $\mathrm{CI}$ engine block requires considerably less energy. The excess energy spent for the manufacturing of Al-alloy engine blocks should be compensated for by the fact that the vehicle is lighter and, thus, consumes less energy during its use.

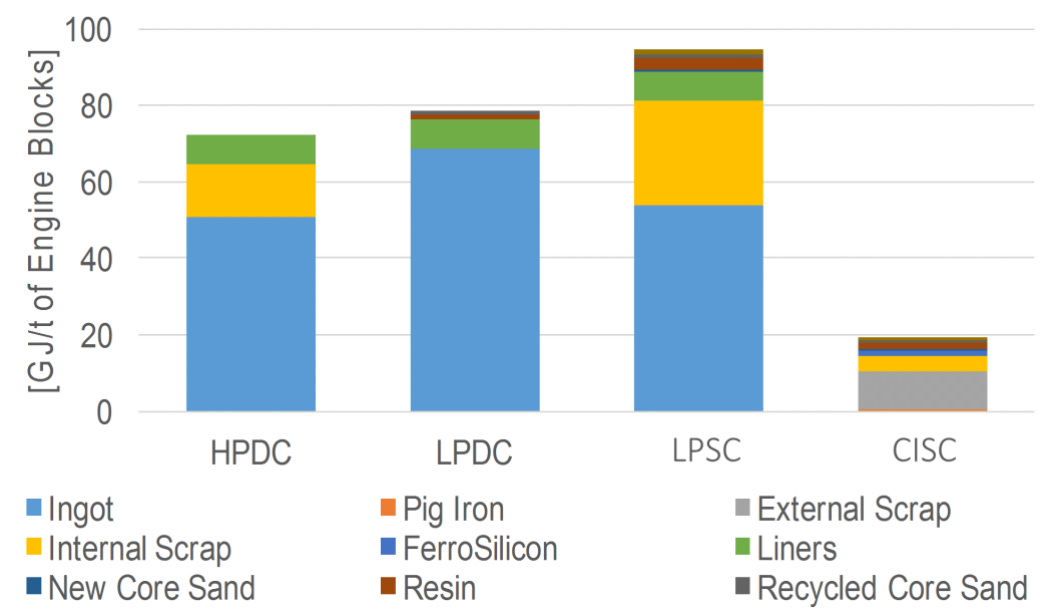

Figure 22. Embodied material energy per ton of engine blocks. 


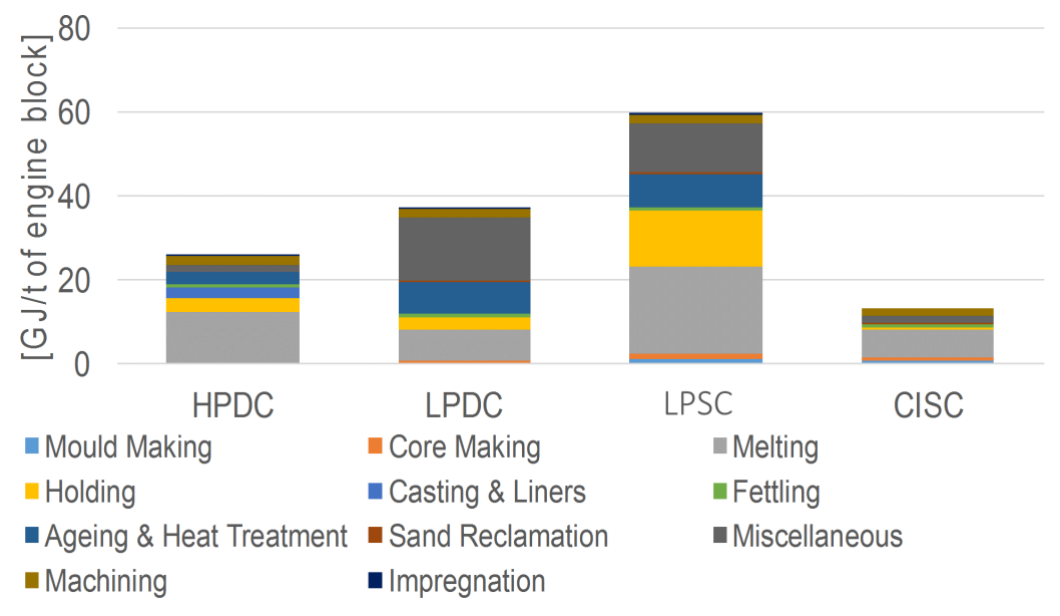

Figure 23. Process energy per ton of engine blocks.

Figures 22 and 23 provide information about the embodied and process energy per ton of engine block. However, it is equally significant to represent the data above using a single block as a functional unit. The values of process, embodied, and total energy, which is equal to the sum of the embodied and process energy, required for the production of each single engine block via the four manufacturing processes, are listed in Table 11.

Table 11. Total energy per engine block. HPDC—high-pressure die casting; LPDC—low-pressure die casting; LPSC—-low-pressure sand casting; CISC — cast-iron sand casting.

\begin{tabular}{ccccccccc}
\hline & \multicolumn{2}{c}{ HPDC } & \multicolumn{2}{c}{ LPDC } & \multicolumn{2}{c}{ LPSC } & \multicolumn{2}{c}{ CISC } \\
\cline { 2 - 9 } & Diesel & Petrol & Diesel & Petrol & Diesel & Petrol & Diesel & Petrol \\
\hline Process energy (GJ/t) & 25.8 & 25.8 & 36.78 & 36.78 & 59.12 & 59.12 & 13.11 & 13.11 \\
Embodied energy (GJ/t) & 72.37 & 72.37 & 78.63 & 78.63 & 114 & 114 & 19.46 & 19.46 \\
Weight of single block (kg) & 27 & 18 & 27 & 18 & 27 & 18 & 38 & 27 \\
Process energy (GJ/block) & 0.64 & 0.41 & 0.91 & 0.58 & 1.46 & 0.93 & 0.5 & 0.35 \\
Embodied energy (GJ/block) & 1.79 & 1.14 & 1.94 & 1.24 & 2.81 & 1.79 & 0.74 & 0.53 \\
Total energy (GJ/block) & 2.43 & 1.54 & 2.85 & 1.81 & 4.28 & 2.72 & 1.24 & 0.88 \\
\hline
\end{tabular}

The embodied energy due to manufacturing and use is illustrated in Figure 24 (shown for the case of diesel engines; similar results were attained for petrol engines). The starting values of the embodied energy correspond to the total energy of the manufacturing process (Table 11). It is evident that the vehicle would have to be driven more in order for the lightweighting to yield benefits. This is due to the much higher embodied energy of $\mathrm{Al}$ alloys compared with $\mathrm{CI}$ as a result of the huge energy content during both the electrolysis and bauxite conversion stages of the production of aluminum.

The distance needed to be covered by a vehicle in order to compensate for the additional energy due the manufacturing and primary production of the engine block is estimated using the break-even distance $(B E D)$ according to

$$
B E D=\frac{\Delta P E B}{\left(\delta F_{s} \cdot E_{f} \cdot \Delta M\right)} \cdot 10^{4},
$$

where $\triangle P E B(M J)$ is the difference in the process energy burden between the manufacturing process with the lowest total energy (CISC) and the rest of the processes, $\delta F_{s}$ is the fuel savings, $E_{f}$ is the energy content of the fuel, and $\Delta M$ is the engine block weight differential (Table 12). The values of the break-even distance for the two types of engine blocks (diesel and petrol) and the various manufacturing processes under examination are summarized in Table 13. 


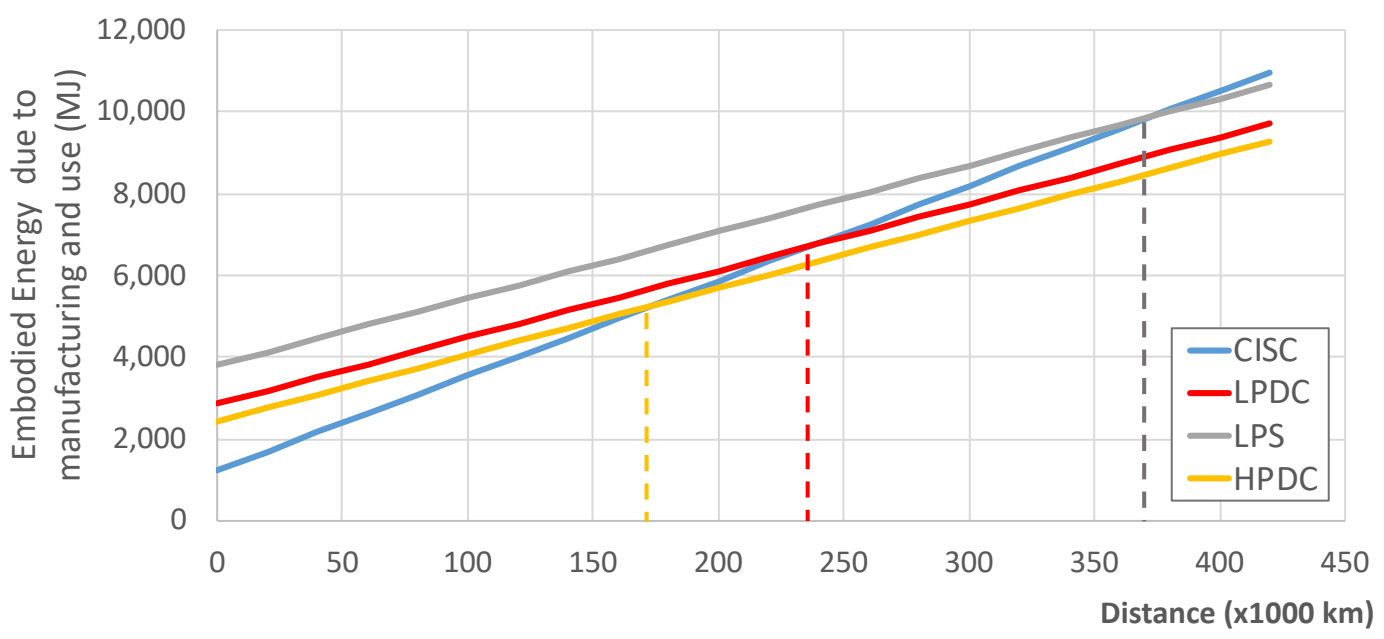

Figure 24. Break-even distance for paying back the lightweight material (for a diesel automotive vehicle of $1200 \mathrm{~kg}$ with an average consumption of 7l,100 km).

Table 12. Parameters for the break-even distance (BED) calculation.

\begin{tabular}{ccc}
\hline & Diesel & Petrol \\
\hline$\delta F_{S}\left(\frac{L}{100 \mathrm{~km} \times 100 \mathrm{~kg}}\right)$ & 0.2 & 0.25 \\
$E_{f}\left(\frac{M J}{L}\right)$ & 38.6 & 34.2 \\
$\Delta M(k g)$ & 9 & 7 \\
\hline
\end{tabular}

Table 13. BED (km) vs. CISC for various types of engine blocks and manufacturing processes.

\begin{tabular}{ccc}
\hline & Diesel & Petrol \\
\hline HPDC & 170,889 & 110,611 \\
LPDC & 232,141 & 155,809 \\
LPSC & 369,221 & 256,960 \\
\hline
\end{tabular}

\section{Conclusions}

Currently, the legislation around the automotive industry is focused on the reduction of tailpipe emissions of vehicles and does not consider the production phase of automotive components. Automotive companies are compelled to pursue a lightweighting and engine-downsizing design strategy to comply with the steadily more stringent targets in emission standards. The objective of this investigation was to perform a thorough life-cycle analysis of an automotive component (engine block) made of two different materials, $\mathrm{CI}$ and $\mathrm{Al}$ alloy, in order to review the potential energy savings of lightweighting.

The "cradle-to-grave" approach was adopted to calculate the overall energy requirements, including the energies for the production of the raw materials, while acknowledging the embodied energy from the initial manufacture up to the final disposal. Our results indicate that the energy required for the primary production and manufacture of $\mathrm{CI}$ engine blocks is much lower compared to the Al-alloy engine case. On the other hand, Al-alloy blocks are more lightweight and contribute to the increase in fuel savings during the use phase of the particular component.

In order to evaluate the effects of lightweighting on the overall energy consumption during the component's life cycle, the weighted average break-even distance (required to compensate for the extra energy consumption in Al-alloy engine blocks) was estimated and found to be around $175,000 \mathrm{~km}$. The breakeven distance fluctuated between 175,000 and 370,000 km for a diesel and between 115,000 km and 260,000 km for a petrol engine block. The conclusion drawn is that, compared to an average passenger vehicle life of 200,000 km, for the LPDC and LPSC processes, the vehicle will 
never recover the extra energy in the Al-alloy engine blocks while being on the road. Therefore, the substitution of materials, traditionally used in the automotive industry, with lighter ones should be very carefully considered.

Author Contributions: Conceptualization, M.J. and K.S.; methodology, M.J. and K.S.; validation, E.P. and M.P.; formal analysis, all; investigation, all; writing-original draft preparation, K.S.; writing—review and editing, M.P.; visualization, E.P.; supervision, M.J. and K.S.

Funding: This research was partially funded by the UK EPSRC projects "Small Is Beautiful" and "Energy Resilient Manufacturing 2: Small Is Beautiful Phase 2 (SIB2)" for funding this work under grants EP/M013863/1 and EP/P012272/1, respectively.

Acknowledgments: The authors would like to acknowledge the UK EPSRC projects "Small Is Beautiful" and "Energy Resilient Manufacturing 2: Small Is Beautiful Phase 2 (SIB2)". Earlier versions of this manuscript were presented at the 38th International Vienna Motor Symposium, Vienna, Austria in 2017 [11] and the TMS Annual Meeting and Exhibition in 2018 [12].

Conflicts of Interest: The authors declare no conflicts of interest.

\section{References}

1. Davies, G. Materials for Automobile Bodies; Butterworth-Heinemann: Oxford, UK, 2012.

2. ACEA European Automobile Manufacturers' Association. Reducing $\mathrm{CO}_{2}$ Emissions from Cars and Vans; ACEA European Automobile Manufacturers' Association: Brussels, Belgium, 2015.

3. Ashby, M.; Coulter, P.; Ball, N.; Bream, C. The CES EduPack Eco Audit Tool-A White Paper 2009; Granta Publications: London, UK, 2009.

4. Sorger, H.; Schöffmann, W.; Wolf, W.; Steinberg, W. Lightweight design of cast iron cylinder blocks. MTZ Worldw. 2015, 76, 22-27. [CrossRef]

5. Salonitis, K.; Ball, P. Energy efficient manufacturing from machine tools to manufacturing systems. Procedia CIRP 2013, 7, 634-639. [CrossRef]

6. Salonitis, K.; Zeng, B.; Mehrabi, H.A.; Jolly, M. The challenges for energy efficient casting processes. Procedia CIRP 2016, 40, 24-29. [CrossRef]

7. Salonitis, K.; Jolly, M.R.; Zeng, B.; Mehrabi, H. Improvements in energy consumption and environmental impact by novel single shot melting process for casting. J. Clean. Prod. 2016, 137, 1532-1542. [CrossRef]

8. Salonitis, K.; Jolly, M.; Zeng, B. Simulation based energy and resource efficient casting process chain selection: A case study. Procedia Manuf. 2017, 8, 67-74. [CrossRef]

9. Pagone, E.; Jolly, M.; Salonitis, K. The development of a tool to promote sustainability in casting processes. Procedia CIRP 2016, 55, 53-58. [CrossRef]

10. Pagone, E.; Salonitis, K.; Jolly, M. Energy and material efficiency metrics in foundries. Procedia Manuf. 2018, 21, 421-428. [CrossRef]

11. Jolly, M.; Salonitis, K. Primary manufacturing, engine production and on-the-road $\mathrm{CO}_{2}$ : How can the automotive industry best contribute to environmental sustainability. In Proceedings of the 38th International Vienna Motor Symposium, Vienna, Austria, 27-28 April 2017.

12. Gonçalves, M.; Jolly, M.R.; Salonitis, K.; Pagone, E. Resource Efficiency Analysis of High Pressure Die Casting Process. In Proceedings of the TMS Annual Meeting \& Exhibition, Phoenix, AZ, USA, 11-15 March 2018; pp. 1041-1047.

13. Brimacombe, L.; Coleman, N.; Honess, C. Recycling, reuse and the sustainability of steel. Millenium Steel 2005, 446, 3-7.

14. Allwood, J.M.; Cullen, J.M.; Carruth, M.A.; Cooper, D.R.; McBrien, M.; Milford, R.L.; Moynihan, M.C.; Patel, A.C.H. Sustainable Materials: With Both Eyes Open; UIT Cambridge: Cambridge, UK, 2012.

15. Balomenos, E.; Panias, D.; Paspaliaris, I. Energy and exergy analysis of the primary aluminum production processes: A review on current and future sustainability. Miner. Process. Extr. Metall. Rev. 2011, 32, 69-89. [CrossRef]

16. Association, A. Aluminum: The Element of Sustainability; A North American Aluminum Industry Sustainability Report; The Alumininum Association: Arlington, VA, USA, 2011; p. 33.

17. World Aluminium—Alumina Production. Available online: http://www.world-aluminium.org/statistics/ alumina-production/ (accessed on 1 June 2019). 
18. Saur, K. Life Cycle Assessment of Aluminium: Inventory Data for the Worldwide Primary Aluminium Industry; International Aluminium Institute: London, UK, 2003.

19. Green, J.A.S. Aluminum Recycling and Processing for Energy Conservation and Sustainability; ASM International: Materials Park, OH, USA, 2007.

20. PE Americas. Life Cycle Impact Assessment of Aluminum Beverage Cans; Aluminum Association, Inc.: Washington, DC, USA, 2010.

21. Alcoa. Transforming Annual Report; Alcoa Corporate Center: Pittsburgh, PA, USA, 2014.

22. Margolis, N.; Sousa, L. Energy and Environmental Profile of the US Aluminum Industry; US Department of Energy: Washington, DC, USA, 2017.

23. European Aluminium Association. Environmental Profile Report for the European Aluminium Industry; European Aluminium Association: Brussels, Belgium, 2013.

24. International Aluminium Institute. Aluminium for Future Generations; International Aluminium Institute: London, UK, 2009.

25. Scarsella, A.A.; Noack, S.; Gasafi, E.; Klett, C.; Koschnick, A. Energy in alumina refining: Setting new limits. In Light Metals 2015; Springer: Cham, Switzerland, 2015; pp. 131-136.

26. Moya, J.A.; Boulamati, A.; Slingerland, S.; Van Der Veen, R.; Gancheva, M.; Rademaekers, K.M.; Kuenen, J.J.P.; Visschedijk, A.J.H. Energy Efficiency and GHG Emissions: Prospective Scenarios for the Aluminium Industry; European Commission, Joint Research Centre, Institute for Energy and Transport: Brussels, Belgium, 2015.

27. Wurtemberg, J.M.V. Lightweight Materials for Automotive Applications; Sintercast: Pully, Switzerland, 1994.

28. Rio Tinto Minerals. 2012 Sustainable Development Report; Rio Tinto Minerals: Greenwood Village, CO, USA, 2013.

29. Alcoa Canada. Outlook on Sustainability 2013; Alcoa Canada: Montréal, QC, Canada.

30. Moll, S.; Acosta, J.; Schütz, H.; Ritthoff, M. Iron and Steel-A Materials System Analysis; European Topic Centre on Resource and Waste Management: Copenhagen, Danmark, 2005.

31. Hasanbeigi, A. Emerging Energy-Efficiency and Carbon Dioxide Emissions-Reduction Technologies for the Iron and Steel Industry; Berkeley Lab: Berkeley, CA, USA, 2013.

32. Norgate, T.; Haque, N. Energy and greenhouse gas impacts of mining and mineral processing operations. J. Clean. Prod. 2010, 18, 266-274. [CrossRef]

33. De la Torre de Palacios, L. Natural resources sustainability: iron ore mining. Dyna 2011, 78, 227-234.

34. Tracking Industrial Energy Efficiency and $\mathrm{CO}_{2}$ Emissions; International Energy Agency: Paris, France, 2007.

35. Bettinger, D. Energy Efficiency in Iron \& Steelmaking; SusChem: Linz, Austria, 2011.

36. Fruehan, R.J.; Fortini, O.; Paxton, H.W.; Brindle, R. Theoretical Minimum Energies to Produce Steel for Selected Conditions; Carnegie Mellon University: Pittsburgh, PA, USA, 2000.

37. U.S. Department of Energy. Bandwidth Study on Energy Use and Potential Energy Saving Opportunities in U.S. Iron and Steel Manufacturing; U.S. Department of Energy: Washington, DC, USA, 2015.

38. De Paula, G.M. Produção Independente de Ferro-Gusa ("Guseiros"); Núcleo de Estudos de Economias de Baixo Carbono: Ribeirão Preto, Brazil, 2014.

39. Americal Iron and Steel Institute Steel Production. Available online: https:/www.steel.org/steel-technology/ steel-production (accessed on 1 June 2019).

40. International Energy Agency. Tracking Clean Energy Process 2015; International Energy Agency: Paris, France, 2015.

41. University of Tennessee-Center for Clean Products. Limestone Quarrying and Processing: A Life-Cycle Inventory; Natural Stone Council: Hollis, NH, USA, 2008.

42. IEA. Global Industry Dialogue and Expert Review Workshop; International Energy Agency: Paris, France, 2014.

43. Price, L.; Phylipsen, D.; Worrell, E. Energy Use and Carbon Dioxide Emissions in the Steel Sector in Key Developing Countries; Lawrence Berkeley National Laboratory, University of California: Berkeley, CA, USA, 2001.

44. Hasanbeigi, A.; Jiang, Z.; Price, L. Analysis of the Past and Future Trends of Energy Use in Key Medium-and Large-Sized Chinese Steel Enterprises, 2000-2030; Berkeley Lab.: Berkeley, CA, USA, 2013.

45. Worrell, E.; Price, L.; Neelis, M.; Galitsky, C.; Nan, Z. World Best Practice Energy Intensity Values for Selected Industrial Sectors; Berkeley Lab.: Berkeley, CA, USA, 2007.

46. Mock, P. EU CO $\mathrm{CO}_{2}$ Standards for Passenger Cars and Light-Commercial Vehicles; International Council on Clean Transportation: Berlin, Germany, 2014.

47. Trechow, P. Windstrom treibt Erdgasfahrzeuge an; VDI Nachrichten: Düsseld, Germany, 2011. 
48. MAG-Manufacturing Technology. Available online: http://www.mag-ias.com/web/en/index.php (accessed on 28 May 2019).

49. Sverdrup, H.U.; Ragnarsdottir, K.V.; Koca, D. Aluminium for the future: Modelling the global production, market supply, demand, price and long term development of the global reserves. Resour. Conserv. Recycl. 2015, 103, 139-154. [CrossRef]

50. CES Edupack. Available online: https://grantadesign.com/education/ces-edupack/ (accessed on 1 June 2019).

51. Fenyes, M. Maximising sand recovery in the foundry. In Transactions of 58th IFC; Ahmedabad, India, 2010; pp. 49-54.

52. Jolly, M. 1.18 - Castings. In Comprehensive Structural Integrity; Milne, I., Ritchie, R.O., Karihaloo, B., Eds.; Pergamon: Oxford, UK, 2003; pp. 377-466. ISBN 978-0-08-043749-1.

53. Ye, H. An overview of the development of al-si-alloy based material for engine applications. J. Mater. Eng. Perform. 2003, 12, 288-297. [CrossRef]

54. Boin, U.M.J.; Bertram, M. Melting standardized aluminum scrap: A mass balance model for europe. JOM 2005, 57, 26-33. [CrossRef]

(C) 2019 by the authors. Licensee MDPI, Basel, Switzerland. This article is an open access article distributed under the terms and conditions of the Creative Commons Attribution (CC BY) license (http://creativecommons.org/licenses/by/4.0/). 